'Servicio de Medicina, Sección de Nefrología, Hospital Naval Almirante Nef. Viña del Mar, Chile.

${ }^{2}$ Departamento de Medicina, Escuela de Medicina, Universidad de Valparaíso. Valparaíso, Chile. ${ }^{3}$ Departamento de Nefrología, Escuela de Medicina, Pontificia Universidad Católica de Chile, Santiago, Chile. Trabajo no recibió financiamiento. Los autores declaran no tener conflictos de interés.

Recibido el 6 de noviembre de 2018, aceptado el 22 de abril de 2019.

Correspondencia a: Jorge Vega 5 Norte 1035 Viña del Mar, Chile. jvegastieb@gmail.com

\section{Efectos en la función renal de la suplementación de creatina con fines deportivos}

\author{
JORGE VEGA ${ }^{1,2}$, JUAN PABLO HUIDOBRO E. ${ }^{1,3}$

\section{Effects of creatine supplementation} \\ on renal function
}

\begin{abstract}
Creatine supplements may transitorily rise serum creatinine levels and mimic a kidney disease. If its use is associated with a high protein diet, the resulting increase in blood urea nitrogen will increase the confusion. Since clinical laboratories usually inform the estimated glomerular filtration rate based on serum creatinine, its elevation may lead to over diagnose a chronic renal failure, with the inherent personal and public health consequences. Creatine supplements are safe and do not cause renal disease. Reports of kidney damage associated with its use are scanty. However, creatine supplements should not be used in people with chronic renal disease or using potentially nephrotoxic medications.
\end{abstract}

(Rev Med Chile 2019; 147: 628-633)

Key words: Creatine; Creatinine; Dietary Supplements; Glomerular Filtration Rate; Renal Insufficiency.
L os suplementos nutricionales de creatina (CR) son utilizados frecuentemente por las personas que hacen regularmente ejercicios físicos, fisicoculturistas y por deportistas profesionales como sustancia ergogénica ${ }^{1-3}$. Su uso se popularizó en las olimpiadas de Barcelona en 1992 y está aceptado como un producto lícito por la agencia mundial antidoping ${ }^{1,4}$.

La suplementación de CR ha demostrado beneficios en el aumento de la masa muscular y de su contenido en los músculos, en el desarrollo de mayor potencia y aumento en las fuerzas durante el ejercicio y menor fatiga durante los entrenamientos. Los atletas que más se benefician son los que hacen ejercicios de alta intensidad y corta duración (Ej: sprinting, saltos) $)^{1,5,6}$.

Desde que su uso se hizo masivo entre los deportistas (se venden anualmente más de 400 millones de dólares en suplementos de CR) se ha planteado que su suplementación pudiera tener efectos deletéreos sobre la función renal ${ }^{1-3,7-13}$.
El propósito de esta revisión es exponer el conocimiento actual sobre los efectos renales del uso de suplementos nutricionales de CR.

\section{Creatina}

La CR es un ácido orgánico nitrogenado (C4H9N3O2) que proviene de dos fuentes: síntesis hepática (en menor medida renal y pancreática) mediante la utilización de 3 aminoácidos (arginina, glicina y metionina) y desde la dieta, por ingestión de carnes rojas y pescados ${ }^{1,5,9,11}$.

El contenido de CR de un adulto de $70 \mathrm{~kg}$ es aproximadamente $120-140 \mathrm{~g}^{5}$. La producción hepática diaria es de alrededor de $2 \mathrm{~g}$ y la ingesta diaria con una dieta normal con carne es de $1 \mathrm{~g}^{8,9,11}$. El 95\% se encuentra en los músculos y el resto en riñón, hígado, cerebro y testículos ${ }^{1,5,11}$. La CR almacenada en el músculo está en $40 \%$ como CR y en $60 \%$ como fosfocreatina. Diariamente entre 1 y $3 \%$ del contenido total de CR (ambas formas) 
se transforma espontáneamente (sin participación enzimática) de manera constante e irreversible en creatinina (CRN) (Figura 1), la cual pasa a la sangre, es filtrada por los glomérulos y excretada en la orina. Una proporción variable de la CRN es secretada por el túbulo proximal por la vía de secreción de aniones orgánicos ${ }^{1}$.

En el músculo esquelético, el ATP reacciona con la CR mediante la participación de la enzima creatinkinasa formándose ADP y fosfocreatina (Figura 1). Esta última molécula no puede salir del músculo y constituye un reservorio para las necesidades futuras de energía. Cuando el ATP es utilizado o cuando el $\mathrm{pH}$ en el músculo disminuye, ocurre la reacción inversa y se genera nuevamente $\mathrm{ATP}^{11}$. Ello ocurre durante los primeros 10 segundos de los ejercicios de corta duración, cuando las fuentes endógenas de ATP están depletadas y la glicolisis aún no ha podido generar ATP dentro de la célula muscular ${ }^{1,2,8,9}$.

\section{Suplementación de creatina}

Hay evidencia que la cantidad de CR almacenada en los músculos puede ser un factor limitante en el rendimiento en los ejercicios de alta intensidad y corta duración, por lo que la suplementación de CR pudiera ser útil para aumentar la resíntesis de ATP hasta en $30 \%{ }^{4}$. Se estima que la suplementación de CR acorta el tiempo de recuperación muscular permitiendo entrenamientos más intensos y largos?.

Los vegetarianos y las personas que tienen niveles bajos de $\mathrm{CR}$ en los músculos, parecen tener mayor beneficio que los que los sujetos que inician la suplementación con niveles normales de $\mathrm{CR}$ en su musculatura. El musculo esquelético solo recibe una cantidad limitada de CR por lo que el adicionar una mayor cantidad no eleva sus niveles. El punto de saturación se logra en los primeros días de usar una dosis de carga ${ }^{6}$. Para mejorar el<smiles>CN(CC(=O)O)C(=N)N</smiles>

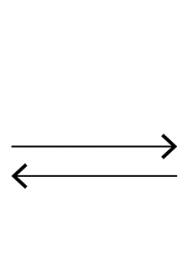

CREATINA

CREATINKINASA<smiles>NP(=O)(O)O</smiles><smiles></smiles>

FOSFOCREATINA

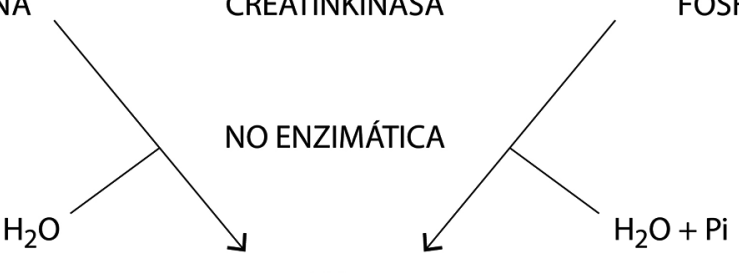<smiles>CN1CC(=O)NC1=N</smiles>

CREATININA

Figura 1. Conversión reversible de creatina a fosfocreatina mediante fosfato inorgánico por acción de la enzima creatinkinasa. La reacción inversa produce ATP desde ADP y creatinina como producto de desecho, que es excretado en la orina. 
rendimiento atlético se suele usar una dosis de carga de $20-30 \mathrm{~g}$ de CR por día (0,3 g/kg de peso) por 4 -7 días (repartidos en 4 tomas) y luego una dosis de mantención de 3-5 g (o 0,1 g/kg de peso) diarios, por tiempos variables ${ }^{8,11}$.

La CR se ofrece comercialmente en forma de diversas sales, las que tienen una alta biodisponibilidad. Sin embargo, la CR no es captada rápidamente por las células musculares y requiere de un transportador para alcanzar el espacio intracelular. Se cree que ingresa junto a glucosa y agua mediada por la insulina ${ }^{1,5}$.

Los suplementos de CR se presentan comercialmente como comprimidos, polvos o solución. Las 3 formas de CR más utilizadas son la CR monohidrato (CR-MH), la CR etil-ester (CR-EE) y la CR alcalina. La CR combinada con carbohidratos simples aumenta los niveles de CR muscular respecto a cuando se la ingiere sola ${ }^{6}$. La cafeína disminuye sus efectos beneficiosos durante el entrenamiento ${ }^{6}$. La CR hace que los músculos extraigan agua del organismo cuando se consume. Ello origina el aumento de peso que se produce en los primeros días y que se debe al aumento en el contenido de agua en los músculos y no a un aumento en la masa muscular. Ello puede ser contraproducente en algunas actividades como la natación y carreras ${ }^{14}$. Por ello se recomienda aumentar la ingesta de agua cuando se utilizan suplementos de CR y se desaconseja su uso en ambientes calurosos por el riesgo de deshidratación ${ }^{6}$. La CR-EE, aparecida el año 2003, es más lipofílica que la CR-MH y se pensó que por ello atravesaría más fácilmente las membranas celulares y se incorporaría más rápidamente a los músculos, sin aumentar su contenido de agua. Sin embargo, una proporción importante de ella es degradada a CRN en el estómago con $\mathrm{pH}$ ácido, siendo posteriormente absorbida en el intestino y eliminada por la orina. Por ello, años más tarde comenzó a comercializarse la CR alcalina, para evitar este inconveniente ${ }^{1}$. Para aumentar la captación y transporte intracelular de la CR a los músculos se han desarrollado otras formulaciones con el objeto de potenciar o hacer un bypass al transportador, combinando la CR con sodio, carbohidratos, magnesio o alcohol esterificado 5 .

El uso de la CR como suplemento nutricional ha producido algunas interrogantes en los médicos y en sus usuarios, que mediante la revisión de la literatura disponible intentaremos responder.

\section{¿Puede la suplementación de creatina simular una enfermedad renal?}

Sí. En los últimos años es frecuente que los laboratorios clínicos, cuando se les solicita una determinación de CRN sérica, informen la velocidad de filtración glomerular estimada (eVFG), calculada con fórmulas que incluyen entre sus componentes la concentración de CRN. Por ello, cualquier factor que eleve su concentración independiente de cambios en la función renal, originará una estimación de la eVFG inferior a la real, pudiéndose diagnosticar erróneamente una enfermedad renal y/o insuficiencia renal, con consecuencias emocionales importantes para los pacientes, sobrecarga asistencial y aumento en los gastos de los sistemas de salud (interconsultas a especialistas, repetición de exámenes, solicitud de imágenes, etc. $)^{8,9,15}$.

Existen en la literatura varias comunicaciones acerca del diagnóstico erróneo de nefropatía y de sospecha de nefrotoxicidad por drogas, originadas en la suplementación de CR con fines deportivos ${ }^{1,3,6,8,9,10}$. La CR no es considerada un medicamento y por ello habitualmente su ingesta no es mencionada por los pacientes ni tampoco es preguntada por los médicos ${ }^{16}$.

Williamson et al., comunicaron el caso de un hombre que consultó por edema de una pierna. Tenía una CRN sérica de 2,2 mg/dl y una eVFG de $33 \mathrm{ml} / \mathrm{min}$. Una semana más tarde su CRN fue 2,56 mg/dl y la eVFG $28 \mathrm{ml} / \mathrm{min}$. La evaluación por especialista no mostró otras alteraciones renales. El paciente relató entrenar 5 veces por semana e ingerir 8 tabletas diarias de CR-EE (32 g) desde hacía 4 meses. Se le indicó suspender los suplementos de CR-EE y 2 semanas después su CRN fue $1,17 \mathrm{mg} / \mathrm{dl}$ y la eVFG $70 \mathrm{ml} / \mathrm{min}$. Se concluyó que la ingesta de CR-EE fue responsable de la elevación de la CRN y del diagnóstico erróneo de insuficiencia renal aguda9.

Velema et al., comunicaron el caso de un hombre que consultó por infertilidad. En sus exámenes destacó una CRN de $2,8 \mathrm{mg} / \mathrm{dl}$ y una leve elevación de la uremia. La evaluación renal no mostró alteración alguna. Refirió entrenar 4 veces por semana e ingerir batidos proteicos y CR-EE. Se le indicó suspender los suplementos y 6 días más tarde la CRN fue $0,85 \mathrm{mg} / \mathrm{dl}$ y la uremia normal. Se concluyó que la elevación de la CRN se debió a los suplementos de CR-EE ${ }^{16}$. 
Willis et al., reportó el caso de un hombre que consultó por un cuadro viral prolongado diagnosticándose una infección por HIV. Su función renal era normal. Un mes después de iniciarse la terapia anti-retroviral su CRN fue $1,88 \mathrm{mg} / \mathrm{dl}$ y la eVFG $41 \mathrm{ml} / \mathrm{min}$. Se sospechó una nefropatía relacionada a HIV o un efecto secundario a droga. La evaluación renal fue normal. El paciente refirió estar asistiendo a un gimnasio y consumir $24-30 \mathrm{~g}$ de suplementos proteicos y 5-10 g de CR-MH. Se le indicó suspender los suplementos y la CRN descendió a $1,33 \mathrm{mg} / \mathrm{dl}$ y la eVFG subió a $61 \mathrm{ml} /$ min. Se concluyó que los suplementos fueron responsables de la alteración. En los seis meses siguientes los autores observaron 3 casos similares ${ }^{8}$.

Jackson et al., comunicaron el caso de un hombre de 20 años con función renal previa normal que ingresó al hospital con una CRN de 2,3 mg/ dl y BUN normal. La evaluación renal no mostró alteraciones. Refirió ingerir desde hacía 4 meses una solución líquida de CR en dosis entre 6 y $12 \mathrm{~g}$ diarios durante los 3 meses previos. En las horas siguientes a la admisión la CRN descendió rápidamente, normalizándose $(0,9 \mathrm{mg} / \mathrm{dl})$ a las 17 h de la hospitalización ${ }^{3}$.

La CR ingerida como suplemento se degrada por vía no enzimática a CRN (Figura 1). Esto puede elevar los valores séricos de CRN transitoriamente, desproporcionadamente respecto a la uremia, pudiendo inducir a la sospecha de una nefropatía ${ }^{7}$.

Feigenbaum et al., con el fin de conocer si los suplementos de CR producían una elevación significativa en los niveles de CRN sérica y urinaria, tomaron a 25 voluntarios sanos los que recibieron una carga de $10 \mathrm{~g}$ de CR-MH y días después igual dosis de CR-EE. En los que recibieron CR-MH, que tenían una CRN basal de $0,97 \mathrm{mg} / \mathrm{dl}$, esta subió hasta $2,49 \mathrm{mg} / \mathrm{dl}$ a las $2 \mathrm{~h}$ y $1,49 \mathrm{mg} / \mathrm{dl} \mathrm{a}$ las $5 \mathrm{~h}$, volviendo a la basal a las $24 \mathrm{~h}$. En los que recibieron CR-EE, que tenían una CRN basal de $0,94 \mathrm{mg} / \mathrm{dl}$, esta subió hasta $6,71 \mathrm{mg} / \mathrm{dl}$ a las $3 \mathrm{~h}$ y $4,94 \mathrm{mg} / \mathrm{dl}$ a las $5 \mathrm{~h}$, normalizándose a las $24 \mathrm{~h}^{1}$. La concentración de creatinina urinaria bajó en las primeras $5 \mathrm{~h}$ en los que recibieron CR-MH y se elevó 5 veces sobre la basal en el mismo período en los que recibieron CR-EE. Concluyeron que los que reciben CR-MH absorben la CR y los que reciben la CR-EE la metabolizan y excretan antes de utilizarla como sustancia ergogénica porque la degradan a CRN en el estómago e intestino (donde se absorbe) y en el plasma por acción de colinesterasas $^{1,9}$.

\section{En los sujetos sanos que usan suplementos de creatina por tiempos prolongados $\underset{\jmath}{ }$ se deteriora su función renal?}

No. Una investigación efectuada por Lugaresi et al., en atletas de ejercicios de resistencia entrenados por no menos de un año y con una alta ingesta proteica $(1,2-3,1 \mathrm{~g} / \mathrm{kg} /$ día $)$ a quienes se les administró CR en dosis de carga y de mantención o placebo por 12 semanas, no mostró cambios en las concentraciones de urea y CRN sérica ni en la velocidad de filtración glomerular medida con $\mathrm{Cr}^{51}$-EDTA ${ }^{17}$. Concluyeron que los suplementos dietéticos eran seguros y que no afectaban la función renal.

Spillane et al, quisieron conocer si la suplementación de CR asociada a un entrenamiento en ejercicios de alta resistencia, en hombres previamente no entrenados, afectaba los niveles séricos de CRN. Tomó a 30 voluntarios los que fueron sometidos a un entrenamiento por $7 \mathrm{se}-$ manas suplementando CR en forma de CC-MH, CR-EE o placebo, con dosis de carga de 20 g/día por 5 días y posteriormente $5 \mathrm{~g} /$ día durante los 42 restantes. Encontraron que la CRN sérica se elevó significativamente durante todo el período en los que recibieron CR-EE, respecto a los que recibieron CR-MH o placebo, en que estuvo en rangos normales. Argumentaron que la CR-EE hizo elevarse la CRN sérica por su degradación gastrointestinal y posterior absorción ${ }^{5}$.

Poortmans et al., tomaron a 9 atletas que regularmente efectuaban entrenamiento en ejercicios extenuantes en los últimos 5 a 10 años y que ingerían suplementos de CR-MH entre 2 y $30 \mathrm{~g}$ diarios por 10 meses a 5 años y los compararon con 85 hombres, estudiantes de educación física o kinesioterapia, que no consumían $C R$ y que fueron el grupo control. Las concentraciones de urea y CRN del plasma y el clearance de CRN no fueron diferentes entre los grupos. Concluyeron que la suplementación de CR por largo tiempo no tenía efectos perjudiciales en la función renal ${ }^{2}$.

Kreider et al., efectuaron un estudio en 98 jugadores de fútbol americano universitario a quienes se les suplementó con CR o un placebo por hasta 21 meses. No hubo diferencias signifi- 
cativas entre los grupos en los niveles de CRN y clearance de CRN. Concluyeron que la suplementación de CR no tenía efectos adversos en la salud de los atletas ${ }^{18}$.

Neves et al., suplementaron con CR o placebo a mujeres postmenopáusicas durante 12 semanas. La función renal evaluada a las 12 semanas con CRN sérica y clearance de EDTA-Cr ${ }^{51}$ no fue diferente a la basal entre los grupos ${ }^{19}$.

Groeneveld et al., efectuaron un estudio doble ciego, controlado con placebo en 175 pacientes con esclerosis lateral amiotrófica (sin evidencias de daño renal) en que administraron $10 \mathrm{~g}$ diarios de CR-MH o placebo durante un período promedio de 310 días. Al final del período no encontraron diferencias entre los grupos en los niveles de nitrógeno ureico ni de albuminuria. Los valores de CRN sérica medidos con HPLC fueron normales. Los autores hicieron notar que cuando la CRN se mide por un método enzimático, la alta concentración de CR en la muestra interfiere en la medición de la CRN elevando sus concentraciones, por lo que este método no debiera usarse cuando se ingiere $\mathrm{CR}^{20}$.

\section{¿Pueden usarse suplementos de creatina en enfermos con patologías renales o con riesgo de padecerlas?}

Hay escasa evidencia disponible al respecto. Un hombre con un síndrome nefrótico recurrente (glomeruloesclerosis focal y segmentaria) sensible a esteroides y que recibía ciclosporina, sufrió una injuria renal aguda 8 semanas después de iniciar la ingesta de CR. Había ingerido CR en una dosis de carga de $15 \mathrm{~g}$ diarios por una semana continuando con 2 gr/día, elevando la CRN a 2,0 mg/dl y reduciendo su clearance de CRN a $54 \mathrm{ml} / \mathrm{min}$. La CR fue suspendida y la función renal se normalizó dentro del $\mathrm{mes}^{21}$.

A un hombre monorreno se le dio una dosis de carga de CR de $20 \mathrm{~g} /$ día por 5 días y luego una de mantención de $5 \mathrm{~g} /$ día por 30 días y se medió su función renal. La CRN sérica subió de 1,03 a $1,27 \mathrm{mg} / \mathrm{dl}$ y el clearance de CRN estimado por la fórmula de Cockroft-Gault bajó desde 88 a $71 \mathrm{ml} /$ min. Sin embargo, el clearance de EDTA-Cr51 no se modificó. Concluyeron que la suplementación de $\mathrm{CR}$ en un monorreno no altera la función renal $^{13}$.

Una recomendación que se puede realizar a la luz de esta evidencia es que la evaluación de la función renal de sujetos que ingieran CR se realice con métodos de referencia (iotalamato o iohexol) o con fórmulas basadas en analitos diferentes a la CRN sérica, como por ejemplo la cistatina $\mathrm{C}^{7}$.

Sin embargo, ante la falta de evidencia disponible, se ha propuesto abstenerse de usar suplementos de CR en pacientes con enfermedad renal o uso de medicamentos nefrotóxicos ${ }^{22}$.

\section{¿Existen comunicaciones de toxicidad renal por el uso de creatina en sujetos sanos?}

Sí. Existen algunas comunicaciones de disfunción renal que se han atribuido al uso de suplementos de CR. Uno ocurrió en un sujeto sano que 4 semanas después de iniciar la suplementación de CR sufrió una injuria renal aguda asociada a proteinuria $4+$ y hematuria + . La biopsia mostró una nefritis intersticial (NI). Con la suspensión de la CR la función renal se normalizón ${ }^{23}$. Otro caso de NI ocurrió en un hombre de 24 años, previamente sano, que ingirió CR y otros suplementos para aumentar su masa muscular. Ingresó en falla renal aguda y con proteinuria. La suspensión de los suplementos de CR permitió que recuperara completamente su función renal ${ }^{24}$. Otro caso ocurrió en un hombre de 18 años que ingirió $20 \mathrm{~g}$ de CR-MH por 5 días y 1 gramo/día por 6 semanas para aumentar su masa muscular. Ingresó al hospital con una CRN de $2,28 \mathrm{mg} / \mathrm{dl}$ y proteinuria de $284 \mathrm{mg} / 24 \mathrm{~h}$. Durante la hospitalización la CRN subió hasta 4,55 mg/dl. La biopsia renal mostró una necrosis tubular aguda. Veinticinco días después de la suspensión de la CR la CRN fue 1,0 mg/ dl y la proteinuria $82 \mathrm{mg} /$ día $^{12}$.

En suma: La utilización de suplementos nutricionales de creatina puede elevar transitoriamente las concentración sérica de creatinina y simular la existencia de una nefropatía. Cuando se asocia el uso de creatina a una dieta alta en proteínas, la elevación del nitrógeno ureico resultante puede aumentar esta sospecha.

Dada la costumbre actual de los laboratorios clínicos de informar la velocidad de filtración glomerular estimada, utilizando fórmulas que incluyen la creatinina, una elevación de la creatinina por esta causa puede inducir a un sobrediagnóstico de insuficiencia renal crónica, con consecuencias 
importantes tanto para los pacientes como para los sistemas de salud.

El uso de suplementos de creatina en sujetos sanos por tiempos prolongados es seguro para la salud y no hay evidencias de que produzca daño renal crónico. Los reportes de nefrotoxicidad son muy escasos en individuos sanos. Se ha recomendado no utilizarlos en sujetos con nefropatías crónicas o que ingieren drogas nefrotóxicas al no existir evidencia suficiente de su seguridad.

\section{Referencias}

1. Feigenbaum J, Hunt K, Hoffman R. Dietary creatine supplements raise serum creatinine mimicking acute kidney injury. Disponible en: https://startingstrength.com/ article/dietary-creatine-supplements-raise-serum-creatinine-mimicking-acute-kidney-injury. (Consultado el 20 de octubre de 2018).

2. Poortmans JR, Francaux M. Long-term oral creatine supplementation does not impair renal function in healthy athletes. Med Sci Sports Exerc 1999; 31: 1108-10.

3. Jackson KA, O’Rourke KM, Kark A, Kennedy GA. Artefactual elevation of creatinine due to creatine water supplements. Med J Aust 2010; 193: 616-7.

4. Perillo Ferreira Carvalho AP, Eckhardt Molina G, Fontana KE. Creatine supplementation associated with resitance training does not alter renal and hepatic functions. Rev Bras Med Esporte 2011; 17: 237-41.

5. Spillane M, Schoch R, Cooke M, Harvey T, Greenwood $\mathrm{M}$, Kreider $\mathrm{R}$ et al. The effects of creatine ethyl ester supplementation combined with heavy resistance training on body composition, muscle performance, and serum and muscle creatine levels. J Int Soc Sports Nutr 2009; 6: 6 .

6. Disponible en: https://medlineplus.gov/druginfo/natural/873.html (Consultado el 20 de octubre de 2018).

7. Gualano B, Ugrinowitsch C, Novaes RB, Artioli GG, Shimizu MH, Seguro AC et al. Effects of creatine supplementation on renal function: a randomized, double-blind, placebo-controlled clinical trial. Eur J Appl Physiol 2008; 103: 33-40.

8. Willis J, Jones R, Nwokolo N, Levy J. Protein and creatine supplements and misdiagnosis of kidney disease. BMJ 2010; 340: b5027.

9. Williamson L, New D. How the use of creatine supplements can elevate serum creatinine in the absence of underlying kidney pathology. BMJ Case Rep 2014. pii: bcr2014204754.

10. Greenhaff P. Renal dysfunction accompanying oral creatine supplements. Lancet 1998; 352 (9123): 233-4.

11. Pline KA, Smith CL. The effect of creatine intake on renal function. Ann Pharmacother 2005; 39: 1093-6.

12. Taner B, Aysim O, Abdulkadir U. The effects of the recomended dose of creatine monohydrate on kidney function. NDT Plus 2011;4: 23-24.

13. Gualano B, Ferreira DC, Sapienza MT, Seguro AC, Lancha AH Jr. Effect of short-term high-dose creatine supplementation on measured GFR in a young man with a single kidney. Am J Kidney Dis 2010; 55: e7-e9.

14. Juhn MS, Tarnopolsky M. Potential side effects of oral creatine supplementation: a critical review. Clin J Sport Med 1998; 8: 298-304.

15. van der Meijden WA, Smak Gregoor PJ. Impaired renal function: be aware of exogenous factors. Ned Tijdschr Geneeskd 2013; 157: A5944.

16. Velema MS, de Ronde W. Elevated plasma creatinine due to creatine ethyl ester use. Neth J Med 2011; 69: 79-81.

17. Lugaresi R, Leme M, de Salles Painelli V, Murai IH, Roschel H, Sapienza MT, et al. Does long-term creatine supplementation impair kidney function in resistance-trained individuals consuming a high-protein diet? J Int Soc Sports Nutr 2013; 10: 26.

18. Kreider RB, Melton C, Rassmussen CJ, Greenwood M, Lancaster S, Cantler EC, et al. Long-term creatine supplementation does not significantly affect clinical markers of health in athletes. Moll Cell Biochem 2003; 244: 95-104.

19. Neves M Jr, Gualano B, Roschel H, Lima FR, Lúcia de Sá-Pinto A, Seguro AC, et al. Effect of creatine supplementation on measured glomerular filtration rate in postmenopausal women. Appl Physiol Nutr Metab 2011; 36: 419-22.

20. Groeneveld GJ, Beijer C, Veldink JH, Kalmijn S, Wokke JHJ, van den Berg LH. Few adverse effects of long-term creatine supplementation in a placebo-controlled trial. Int J Sports Med 2005; 26: 307-13.

21. Pritchard NR, Kaira PA. Renal dysfunction accompanying oral creatine supplements. Lancet 1998; 351 (9111): 1252-3.

22. Yoshizumi WM, Tsourounis C. Effects of creatine supplementation on renal function. J Herb Pharmacother 2004; 4: 1-7.

23. Koshy KM, Griswoldt E, Schneeberger EE. Interstitial nephritis in a patient taking creatine. N Eng J Med 1999; 340: 814-5.

24. Thorsteinsdottir B, Grande JP, Garovic VD. Acute renal failure in a Young weight lifter taking multiple food supplements, including creatine monohydrate. J Ren Nutr 2006; 16: 341-5. 